\title{
Analysis on the characteristics of public opinion in emergency crisis under new environment media
}

\author{
Lin Muying, Qi Kai* \\ School of Management, Harbin Normal University, Harbin 150025, China
}

Keywords: New Media; Social Media; Crisis; Public Opinion

Abstract: Nowadays, the internet has become an integral part of our daily life. Communication is now easier and more efficient than the past. Since the modern era of communications has begun, the world has changed dramatically. Social media is now an alternative platform of media that has been widely used over the past few years. There are various sites that have their own niche markets and specific users. Additionally, social media has transferred from not only personal use but also to the commercial sector, it creates communities which are beneficial to user and can also connect family and friends. The use of social media can sometimes be uncontrollable. It may be useful or harmful, it depends on the information that is displayed on the webpage. The openness of social media may mislead some people in terms of how they understand the information available. This paper is going to examine the benefits of using social media to communicate, and also the disadvantages that may occur and the characteristics of the online societies.

\section{Introduction}

In fact, people are able to use many types of media, but it can also be difficult to compare the different types of media available. To avoid confusion, the information below will clarify these terms.

The difference between traditional media and new media:

Mostly, traditional media is one-way communication, including no interaction with others. It is characterized by cost and refers only to the physical objects instead of digital systems. Cost of production and distribution are highly expensive. The new media is a very new form of communication, using channels to send information in the digital world, through technology. The production costs of creating new media are lower than that of old media.

To summarize, traditional media includes media such as newspapers, magazines, books, radio, television, and other such non-interactive media. New media comprises of blogs, YouTube, EBooks, websites, online video/audio streams, email, online forums, messaging apps, online education, online communities, online social platforms, and much more (Christopher S Penn, 2016).

Social media is a way for people to communicate and interact online. It consists primarily of the Internet and mobile based tools for sharing and discussing information among humans. The term most often refers to activities that integrate technology, telecommunications and social interaction, and the construction of words, pictures, videos, and audio. This interaction, and the manner in which information is presented, depends on the varied perspectives and building of a shared 
meaning among the various communities, as people share their stories and experiences. Businesses also refer to social media as User Generated Content (UGC) (Kristy Bolsinger, 2014).

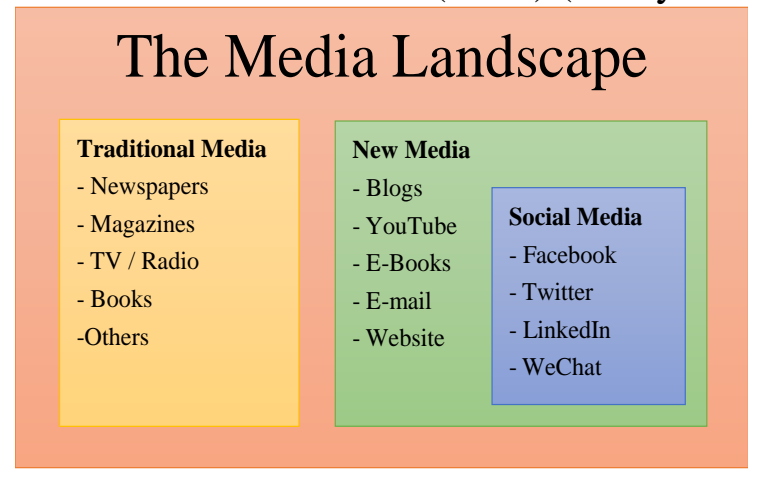

Figure 1 The Media Landscape

Social media are forms of new media, such as Twitter, Facebook, Instagram, Snapchat, Tumblr, LinkedIn, Google Plus, Pinterest, WhatsApp, Tinder, Weibo, WeChat etc..., but not all forms of new media are social media. New media can cover everything that has been changed in the now digitized sharing of information, of course social media is a part of that. It is perhaps the biggest and most influential part in many ways, but still just a part. While new media allows for sharing, the development of social media and its interactive components has made the ability to comment, respond, share, critique, change and add to information possible on a far broader scale. It is the increased visibility of interaction, with largely unfiltered peer-to-peer communication that cannot be easily controlled, that is central to social media (Ariel Robinson, 2016).

Social media is necessarily interactive, focused on social connections, and is designed with social connections in mind. A static website that only sends information out and does not allow for responses may be a form of new media but is not a form of social media. A blog on the other hand, specifically one that can be commented on and shared with others, is a form of social media (Jason Pridmore, 2013).

\section{Crisis and Social Media}

With new environmental developments and terrorism breeding opportunities for crises, and media proliferation and advancement increasing exposure to crises, organizations have placed a higher premium on crisis management.

Crisis is a critical or decisive point at which an organization's response to an issue, accident or emergency threatens the reputation and/or future standing of the organization.

The rise and proliferation of Web 2.0 applications revolutionized the way people interact and collaborate with each other. At the core of the Web 2.0 framework, are the new media and the social media, "a group of Internet-based applications that build on the ideological and technological foundations of Web 2.0, and that allow the creation and exchange of User Generated Content (UGC)" (Dmitry Leykin, 2016). Social media nowadays includes collaborative projects, blogs and microblogs, content communities, social networking sites, virtual game worlds and virtual social worlds. Through these applications, users create online communities to share information, ideas, personal messages, and other content. This user-generated content in a changing and dynamic virtual community creates a massive and unstructured data (Kaplan AM, 2010).

In modern society, the significance of the social media in everyday life has increased dramatically, turning the world into a "global village" (Vasterman P, 2005). Since the late-20th century, new methods of mass media including the internet, cellular technologies and personal portable devices, have been considered as fulfilling a significant role in agenda setting and framing, 
creating social capital, and affecting politics, society and culture. According to a recent report that summarizes social, digital \& mobile statistics among global users (Kemp S, 2015), 42\% of world's population are active internet users, and above one-quarter have active social media accounts. With regard to social networking platforms, the report shows that there are 2.06 billion Facebook users (Van Dam J-W, 2015), 700 million Instagram users, 328 million Twitter users, and 106 million LinkedIn users (Simon T, 2015). Twitter, a microblogging communication platform, for instance, reaches an estimated total of over 50 million tweets per day, and during crisis twitter activity increases exponentially (Terpstra T, 2012).

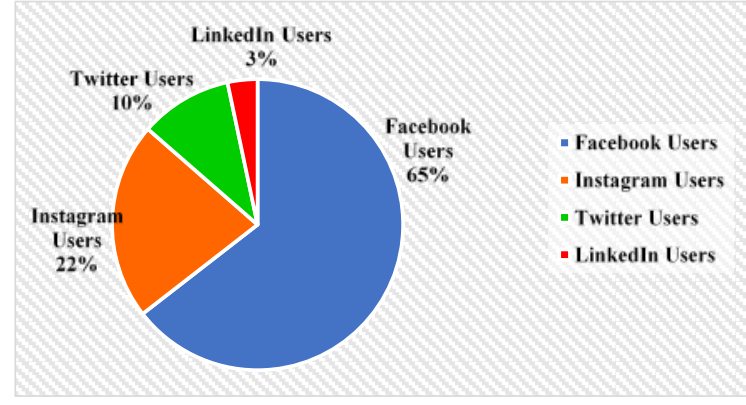

Figure 2 Number of Worldwide Social Media Sites Users

Social media has become an essential mean of communication during disasters and it has been suggested that best practices need to be established to assist organizations, government and decision makers in optimizing risk and crisis communication in this era (Maresh-Fuehrer MM, 2015). Houston et al. developed a framework for the practice and study of disaster social media. They note that disaster social media users in the framework include communities, government, individuals, organisations, and media outlets. Those players seek to gain insights from the massive usergenerated content published in the communication channels, provided by the social media platforms (Houston, 2014). This published timely information is quickly spread across multiple social networks, and may affect, shape or direct public behaviour without official involvement or even in contradiction to formal instructions (Mazer JP, 2015). Although many challenges exist during social media message processing and analysis, (e.g. management of information overload, credibility issues, and prioritizing different classes of messages), state of the art computational methods exist to carry out complex information processing operations (Imran M, 2014).

\section{Social Media as asolving crisis tool}

Social media has been radically changing the communication landscape over the past several years and as a result, crisis communication is undergoing substantial change (Daniel A Landau, 2011). It becomes clear that social media serves as ultimate space for crisis communication processes. Implementation of traditional crisis communication activities was identified as one of the functions of disaster social media (Houston, 2014). A recent survey of about 288 government officials in the US revealed that $71 \%$ of them were using social media during crisis, with Facebook as the popular social media. Officials used social media during various types of crises, including public health, natural disasters, transportation, political, and criminal crises. Researchers found that the degree of social media use, rather than the number of tools used, was positively correlated with local city officials' evaluations of their ability to control a crisis situation and the strength of their responses.

There is the research systematically investigated crisis messages collected from Twitter. Relevant tweets for 26 different crisis situations that took place in 2012 were sampled from the available public twitter stream, and for each situation types of information and sources of that 
information were examined. During crisis situation, eyewitnesses, government, business, media \& news organizations and outsiders participate and publish different information types in social media (Olteanu A., 2015). Types of information include data about affected individuals (e.g. people trapped, people missing), infrastructure \& utilities (e.g. damages, availability of services), donations \& volunteer (e.g. donations of money, requesting help), caution \& advice (e.g. warnings, caution \& advice), sympathy \& emotional support (e.g. concerns and condolences) and other useful information (e.g. flood level, weather). Based on the data of that study, it seems that the Government, being the official source of information during crisis, was responsible for less than 5\% of all published information. Of the applicable information types, the majority (32\%) of the communication efforts by the government were about useful information (32\%) and caution and advice (27\%). Only 6\% of the published tweets concerned about sympathy and support.

The media plays a crucial role in shaping public response to terrorism and other disasters. Effective crisis communication suggests the need of an unhindered but purposeful exchange of information within and between authorities, organizations, media, involved individuals, and groups before, during, and after a crisis. With the changing media environment and the developing online atmosphere, traditional media are shifting to practices that are more adapt to a social media environment. Furthermore, to improve services and communication with the population, each official seek to leverage these new media channels. To emphasize engagement through social media should be more active and reflect a clear response priority in crisis communication plans. Ambiguous or unreliable communications can cause damage and serve to exacerbate publics' mental health reactions and a delay in operational response and recovery. To conclude, it is important to incorporate the use of citizen generated content into any crisis plan and learn to respond to the media and public even quicker than before.

\section{The Impact of Social Media on Public Opinion}

Before we discuss the impact of social media on public opinion, let's first understand what public opinion exactly is. While there are a lot of definitions for Public Opinion, a general definition of Public Opinion is, 'a collection of thoughts and opinions of the majority of a social group'.

I say 'majority' because it is next to impossible for a society to completely share the same opinion regarding a specific subject. Therefore, when we say public opinion, we actually refer to the opinion of the majority of a society.

Public Consultation and Engagement experts answered the following question regarding the impact of social media; "How is social media influencing public opinion, and how far have public and private organisations reached in utilising it towards strengthening their outreach?”

Neil Ellis (2016) commented that "Social media has become one of the largest influencing factors in public opinion. A lot of community members are no longer being engaged through traditional means, such as newspapers and magazines, and depend on social media for their content. Social Media is a great tool for engaging a larger demographic as it reaches a more widespread market. Jobs have been created specifically for social media professionals and a lot of private companies have a Social Media Coordinator on staff. The public is also excelling in social media by having politicians and staff actively using social media, and allow citizens to become thoroughly engaged”.

Jo Nelson (2016) states, "Social media has a varying effect on public opinion depending on the age of the public and their usage of social media. It has a major effect on the opinions of young people. Only a few organizations have the know-how to utilize it effectively".

Moreover, according to Barbara Motzney (2016) commented that "The anonymity and temporary identity loss that can be misused on social media can result in public opinion being 
skewed by seeming opinion leaders - who act like 'trolls' - that post disruptive or inflammatory comments online, or by specific interests posing as individuals. There are techniques to help mitigate the impact of those who would seek to skew the results, but one must always be aware of the impact that 'trolls' can and do have.

"As an employee of a federal government agency, I would have to say that federal government agencies have not, for the most part, harnessed the full potential of social media and for good reason. As public entities accountable to the public, the messaging needs to be accurate and consistent, which by default means that the messaging needs to be reviewed and approved. Though you can have some "in the can responses", it is impossible to create a meaningful response for every scenario and timeliness of response is key in the social media realm. A slow to come answer is akin to no answer at all as the conversation will have moved on to a completely different topic by the time the answer is issued".

\section{Conclusions}

In very fast pace, social media has acquired a prominent role in media and our daily life. During crisis and emergency, people tend to approach social media not only because of the need for quick information, but also due to the human tendency for storytelling, which allows people to experience their lives as coherent, orderly and meaningful. It is what makes people's life more than a blooming, buzzing confusion. Communication with public during emergency is critical for successful emergency management lifesaving, rescue and recovery. On the other hand, one should take into account that 2.08 billion people world-wide are social media users and significant number of people are expected to participate in the online convergence, posting massive amount of user-generated content making it an almost impossible web of information. Using state of the art computational tools makes this mission possible. Being one of the fundamental tools of emergency management, crisis and risk communication play an important role in mitigating, or exacerbating, the psychological and behavioural reactions to critical incidents and disasters. Thus the task of continues monitoring of the social web for crisis related information can significantly improve the efforts of emergency management. This is the reason for officials to be eager to exploit social media content to gain insight from the public for the optimization of risk and crisis communication. Officials should also remember that the most effective communication is those designed for a specific audience. Finally, crisis managers need to acknowledge the potential of the massive generated textual information published during times of emergency in the social media. This knowledge is not only beneficial for situational awareness but also for user profiling, which in our case, is not intended for marketing purposes. Behaviouralanalysed information from text posted on social media can leverage targeted communication during crisis, by automatic target audience characterization and adapted, psycholinguistic matched risk message preparation. Thus, as we keep facing major disasters and emergencies that have become more frequent during the last decade, governments can be more effective in transmission and dissemination of warning messages or/and survival information, better manage different public reactions triggered by the crisis, gain credibility from the public, and improve public cooperation during emergencies.

\section{Acknowledgements}

This project was supported by: 1) Philosophy and Social Science Foundation of Heilongjiang Province (17GLB025); 2) Research Project on Higher Education Reform in Heilongjiang Province (SJGY20170176); 3) Harbin Normal University Youth Research and Development Project (370611704). 


\section{References}

[1] Ariel R., 2016. Social Media, New Media, and Why You Need to Know the Difference

[2] Christopher S. P., 2016. What's the difference between social media and new media [Internet]; Available from URL: http://www.christopherspenn.com/2018/02/whats-the-difference-between-social-media-new-media

[3] Daniel A. L., 2011. How Social Media is Changing Crisis Communication: A Historical Analysis [Internet]; Available from URL: http://www.danlandau.net/writing/sources/research/danlandau_thesis.pdf

[4] Dmitry L., Limor A.D , Mooli L., 2016. Leveraging Social Computing for Personalized Crisis Communication using Social Media [Internet]; Available from URL:https://www.ncbi.nlm.nih.gov/pmc/articles/ PMC4821767/\#idm139936142862864title

[5] Houston, J.B. et al., 2014. Social media and disasters: a functional framework for social media use in disaster planning, response, and research. Disasters., pp.1-22

[6] Imran M, Castillo C, Lucas J, Meier P, Vieweg S., 2014. AIDR: Artificial intelligence for disaster response. 23rd international conference on World Wide Web

[7] Jason P., Annelies F., Isolde S., 2013. New media \& social media: what's the difference [Internet];Available from URL:https://www.linkedin.com/pulse/social-media- new-why-you-need-know-difference-ariel-robinson-1

[8] Kaplan AM, Haenlein M., 2010. Users of the world, unite! The challenges and opportunities of Social Media. Bus Horiz. Elsevier, pp.59-68

[9] Kemp S., 2015. Digital, Social \& Mobile Worldwide in 2015 [Internet]; Available from URL: http:// wearesocial.net/blog/2015/01/digital-social-mobile-worldwide-2015

[10] Kristy B. , Moz S., 2014. The Beginner's Guide to Social Media [Internet]; Available from URL: https://moz.com/beginners-guide-to-social-media

[11] Maresh-Fuehrer MM, Smith R., 2015. Social media mapping innovations for crisis prevention, response, and evaluation. Comput Human Behav

[12] Maresh-Fuehrer MM, Smith R., 2015. Social media mapping innovations for crisis prevention, response, and evaluation. Comput Human Behav

[13] Mazer JP., Thompson B., Cherry J., Russell M., Payne HJ., Gail Kirby E., et al., 2015. Communication in the face of a school crisis: Examining the volume and content of social media mentions during active shooter incidents. Comput Human Behav, pp.238-248

[14] Olteanu A., Vieweg S., Castillo C., 2015. What to Expect When the Unexpected Happens: Social Media Communications Across Crises. In Proc of 18th ACM Computer Supported Cooperative Work and Social Computing (CSCW'15)

[15] Strategy I., 2016. Public Consultation and Engagement.Impact of Social Media [Internet]; Available fromURL:https://www.publicconsultationcanada.com/resources-and-ideas/impact-social-media/

[16] Simon T, Goldberg A, Adini B.,2015. Socializing in emergencies-A review of the use of social media in emergency situations. Int J Inf Manage

[17] Terpstra T, de Vries A, Stronkman R, Paradies GL., 2012. Towards a realtime twitter analysis during crises for operational crisis management. ISCRAM'12: Proceedings of the 9th International ISCRAM Conference

[18] Van Dam J-W, Van de Velden M., 2015. Online profiling and clustering of Facebook users. Decis Support Syst [19] Vasterman P., Yzermans CJ., Dirkzwager AJ., 2005. The role of the media and media hypes in the aftermath of disasters. Epidemiol Rev. Faculty of Humanities, Department of Media Studies, University of Amsterdam, The Netherlands., pp.107-114 